CASE VI. General Fibrous Enlargement of the Thyroid Gland, causing Dyspnac: Unsuccessful Treatment by Counterirritation, Electrolysis, etc.: Treatment by Seton and Mineral Waters: Cure.-Sarah M., aged I3, a native of Louth in Lincolnshire, applied at the Central London Throat and Ear Hospital June 7th, 1875, on account of difficulty of breathing occasioned by enlargement of the neck. The thyroid gland had been observed to become generally and progressively enlarged for the last two years, and for the last six months breathing had been noisy and difficult. She occasionally had a cough of a laryngeal and spasmodic character. Her swallowing had not been difficult or painful; but she constantly felt a lump rising in the throat, with a general sense of constriction. Her general health was good. The bowels were rather constipated, and she had never menstruated. On examination, there was seen to be a general moderately large enlargement of the thyroid gland. The neck measured $153 / 4$ inches.

Ointment of biniodide of mercury was ordered, with iron tonics, and a five-grain pill of aloes and myrrh each night. In the course of two or three months, menstruation was established; but the tumour did not diminish. In January, I commenced a series of experiments with electrolysis, and pursued that treatment on this patient as well as on seven others. [I may mention, in passing, that I only got a really beneficial result in one case and partial diminution in another, both of them being simple glandular enlargement of the non-fibrous variety.]

Sarah M. underwent twelve operations in four weeks, having two needles introduced each time, and a strength of from sixteen to twentyfive cells of a Stöhrer's battery. Not the least good was effected; in fact, both tumour and dyspnœea appeared to increase, so that early in March I introduced a seton right through both lobes and isthmus of the gland. The seton was retained for six weeks; and in June the patient was sent to Woodhall, where I saw her two days ago. She has been an inmate of the Woodhall Hospital for six weeks, taking the baths and water, and wearing the compress; and her general health has improved most markedly. Locally, there is still some slight fulness remaining, but all distress is relieved. The child plays and runs about without any trouble.

\section{THE MILITARY MEDICAL SERVICE OF TURKEY.}

By J O S I A H W I L L I A M S, L. R. C. P. ED., Surgeon to the Central Military Hospital, Sienitza.

Now that Turkey engages a large share of public attention, I think that a few remarks on her military medical service may prove of some interest to many of my medical brethren in England. I have been about three months in the service, and have had a good opportunity of becoming acquainted with the treatment of the wounded and sick, the former more particularly, as few but wounded are admitted into my wards.

Whilst at Constantinople, I crossed the Bosphorus two or three times, and visited the hospital at Scutari. This hospital is splendidly situated on rising grounds, no houses near it, facing the Black Sea. The English cemetery intervenes, and is as nicely kept as any of our London cemeteries. I accompanied the chief physician in his round, and observed that he looks over the food and tastes it before it enters the wards. The wards are wide, long, but not very lofty; they are well lighted, and capable of being well ventilated, but ventilation appears to be a matter of very secondary importance in all the hospitals I have visited. A large wide verandah runs round the outside of the wards the whole length of the building.

The interiors of the wards look clean, and the patients look comfortable and well cared for. The French Pharmacopaia is used in Turkey, and all prescriptions are written in French. The diets range from I to 6 . No. 6 is the highest, and consists of a good supply of meat and rice, and bread. Hushaf, or stewed raisins, is an extra, and is a very favourite thing with the Turks. Mahalabie is also an extra, consisting of rice and raisins, and is often given with No. 5 diet, as that contains less meat. Nos. 1, 2, 3, 4 are soups, or soups and rice. This hospital is a large one, and contains chiefly medical cases. It holds, I think, six or seven hundred beds, but this I am not sure of. The wards are fumigated two or three times a day with incense.

In due time (the Turks never hurry themselves, no matter what it is or how important), I received my commission, and was fortunate in being sent to the front, where severe fighting was going on. I had to pass through Salonica, and thence by rail to Metraniza, thence a four days' journey on horseback to Sienitza, passing through Novi Bazar. The little hospital at Metraniza consisted of a few old haylofts, etc., knocked into one. I found a very large number of troops encamped by this village. Two of the camps were on perfectly flat ground by the side of a river. In wet weather, the place was like a swamp. The latrines are placed much too near the camps, and all around and close to the camp is freely used by the soldiers. The outpatients of this hospital chiefly suffered from ague, dysentery, and diarrhœa. The hospital at Novi Bazar is a large one, and contains four or five hundred beds. The wards are clean, and the chief medical officer here (Oshmed Bey) is, I think, a very suitable man for the position he holds. He has studied in Paris, and seems well up to his work. The privy accommodation here is of a very rude description, and large open gutters convey the freal matter away from the hospital. The inmates of this hospital are chiefly convalescents from Sienitza. I stayed here for two days, and was much struck by the extraordinary number of cases of goître I saw ; many of them very large indeed. I am sure it is no exaggeration to say that every third person has this disease more or less developed.

After resting two days at Novi Bazar, I started for Sienitza. I halted one night in a fortified camp and arrived at Sienitza next day. Before entering the town, we passed by a large encampment of Arab troops-about ten thousand or so. The weather at the time was very hot, and the atmosphere in the neighbourhood was extremely unpleasant to the olfactory nerves. This was easily accounted for, as the calls of nature were relieved all around and close to the camp. The tents were pitched on perfectly flat ground, and were never removed until the rain and snow compelled their removal, and not then until the whole place was like a great dismal swamp. Need I say that dysentery, diarrhœa, ague, rheumatism, and bronchitis engaged our attention very much after this?

The Sienitza Hospital is a short distance from Javor, otherwise called Cantrement, where very severe fighting, under Mehemet Ali Pasha, has lately been going on. The hospital is a large quadrangular building placed in an elevated position overlooking the town. It contains six hundred beds; but, during the late severe battles near here, the floors also were covered with wounded. The whole is under the able superintendence of Ohannes Bey, an Armenian, and a very efficient courteous gentleman, who was much pleased on the arrival of English surgeons here. It has been necessary to occupy about twenty wooden houses here, and the Greek church also, with medical cases. There are about a dozen medical men to attend to the patients. One has to attend the houses, and each of the others has the superintendence of one, two, or three wards.

The visit is made at 8 A.M., accompanied by the pharmatien; his business is to take down the diets and medicines ordered on the patients' cards, and at once make up the medicines and see that they have their proper diets. As my two wards contain very few but surgical cases, my surgeon accompanies me round the wards after I have ordered the diets and medicines. $\mathrm{He}$ has to dress, under my supervision, about one hundred and twenty or one hundred and thirty cases. I ought to explain that my surgeon is equivalent to a dresser in a London hospital. $\mathrm{He}$ has no diploma, but simply learns to dress the wounds and bandage. This one dresses and bandages very nicely, but certainly requires looking after. Any narrow piece of wood wrapped around with one thin layer of wadding will answer his purpose as a splint, and he persists, unless I am there, in plugging a wound with charpie long after it is required, and, in many cases, has caused large sinuses where the wound would have healed up two or t.ree weeks sooner had he not been too officious. We have no lint ; charpie is used and answers quite as well. Sloughy and gangrenous wounds are dressed with cinchona powder and camphor, or decoction of cinchona, and a very good dressing it is too. We have had no carbolic acid, permanganate of potass, or disinfectant of any kind, since $I$ have been here, until within the last three days. Notwithstanding this, we have been very free from gangrene and erysipelas until now. I have had two or three cases of erysipelas within the last few days following wounds of the head. Here they use a mask of some mercurial preparation in the form of an ointment, leaving it on for three or four days and the application is certainly very effective. The absence of gangrene and erysipelas I attribute to the free ventilation of the wards. Every morning, I had a fight about this; but I carried my point until quite lately. Now that the cold weather has set in, not only are the windows nailed down, but every crack is pasted over with paper. At first, I wrenched the nails out, as I could not get any one else to do so, but found them more securely nailed next day, so I have been obliged to give up the unequal contest. As there is no fire-place in the room, the wards smell very offensive in the mornings where so many wounded are crammed together. My wards are each about one hundred feet long by twenty-four feet wide.

A few cases of typhoid fever have cropped up within the last few days, also one case of small-pox. Within the past four weeks, the 
weather has been very severe; heavy falls of snow and severe frost. The Arab troops suffer most severely ; several have been frozen to death, and many have been admitted into hospital with frost-bitten feet ; some have become gangrenous and will require amputation.

Now that the armistice has been agreed to, a great number of battalions have left here, and most of those remaining have been housed, so we shall not have many more of those cases, unless they come from Javor, where, of course, they still live in tents.

We have no wine or brandy in the hospital, and, if we had, I do not think many of our patients would take it, as I believe it is contrary to their religion to do so. They certainly get on just as well without, and my opinion on the free use of stimulants in hospitals has undergone some modification, though, doubtless, those living in crowded cities require them more than these very temperate men living so much in the open air. Conservative surgery is here pushed to its utmost limits, very many preferring death to amputation.

Bayonet-wounds are very rare, and for this reason. Mehemet Ali Pasha, who is an extremely genial and accessible man, told me the other night that, when he has ordered the bugle to sound "cease firing", the Servians have ceased also. The bugle has then sounded "charge bayonets", and, whenever that order was issued, they invariably executed a strategic movement to the rear. I got a few cases of shell-wounds and very few from cannon; nearly all are caused by conical bullets.

I will mention a few of the more curious cases as regards the course of bullets.

A., aged 35. The bullet entered the outer and upper part of the right thigh, passing across the back part of the thigh ; made its exit at the inner side of the thigh ; then it passed across the lower part of the scrotum, slightly abrading it, and then entered the inner side of the left thigh. The soft structures only were injured, and the man has made a good recovery, having been in hospital six weeks.

B., aged 30. The bullet entered the inferior portion of the right buttock, passed around the anterior part of the femur, and made its exit in the right inguinal region. No bones were fractured.

C., aged 32. The entry of the bullet was at the upper and outer side of the left thigh; it passed across the lower part of the abdomen and pubes to the outer side of the right thigh, where I cut down on it and took it out. No bones were fractured.

D., aged 30. The entry of the bullet was at the anterior and middle portion of the arm. It passed up and over the head of the humerus and down to the lower angle of the scapula.

E., aged 34. The bullet entered at the inferior part of the mastoid process on the left side, passing around the head immediately below the occipital protuberance ; it made its exit at the inferior portion of the mastoid process of the right side. No erysipelas supervened, and the man has neariy recovered.

F., aged 32. The bullet entered about an inch and a half below the right nipple, taking a direction downwards and towards the left side. What became of the bullet I do not know. I passed a Nélaton's probe about two inches, following the track, but did not succeed in finding it. This patient has been under my care for six weeks. Soon after admission, he had an attack of pleuropneumonia and diarrhœa. $\mathrm{He}$ is now recovering, and the wound is nearly well.

Very little fever, as a rule, follows very severe injuries; occasionally we have had a case or two of erysipelas following wounds of the scalp; but, considering the crowded state of the hospital, it really is most surprising, that so little gangrene and erysipelas have troubled us. A great number of the wounded from Javor look very anæmic. Food has sometimes not been obtainable there for a day or two, and, during the late severe weather, it has been very difficult to get food for such a large number of men as were at Javor.

They soon rapidly improve under ferruginous preparations and good diet, and their wounds get on well. I find wounds of the upper part of the trunk and upper extremities much more common than of the lower. It is quite astonishing to see the number admitted with indexfingers shot away ; thumbs also, and wounds of the palm of the hand ; and $I$ at first could not account for it. But I soon found what I conseived to be the cause. The Turks, in opening fire on the enemy, lie down, just lifting the head and shoulders. This, of course, would account for the number of wounds about the head and shoulders and down the back, and the great number of compound comminuted fractures of the humerus and radius, and ulna. The latter are much more frequent than of the tibia and fibula, and have every one recovered with useful arms. But the cases of compound comminuted fracture of the tibia and fibula have generally done badly. I have two cases now where the foot and lower part of the leg are almost ready to drop off, but it is impossible to persuade these fellows to submit to amputation.

\section{THERAPEUTIC MEMORANDA.}

\section{LIQUOR FERRI PERCHLORIDI FORTIOR AS A LOCAL APPLICATION IN ERYSIPELAS.}

In the JOURNAL of December gth, Dr. W. Leavens White gives a note on the use of the above applied locally in erysipelas. I used the tinctura ferri perchloridi seventeen years ago as a local application, painting over the whole affected surface, and about half an inch beyond it, with a camel-hair pencil. For the last seven years, I have used equal parts of the liquor ferri perchloridi fortior and water, giving tenminim doses of the tincture of perchloride of iron internally every three hours, and I have never known the remedy to fail. I may state that I have only recently recovered from a very severe attack of erysipelas in the head and face, which was treated in this way with the most favourable results.

$$
\begin{aligned}
& \text { James W. J. Oswald, L.R.C.P.Ed., etc., } \\
& \text { Kennington Road, S.E. }
\end{aligned}
$$

\section{SALICYLIC ACID IN ACUTE RHEUMATISM.}

J. B. HAD been suffering from subacute rheumatism for a week, and was under alkaline treatment. He derived little benefit during this time, and the rheumatism somewhat suddenly assumed the acute form and seized upon all the large articulations. The affected joints were much swollen, very tender and red; all voluntary movement was gone, and there was lancinating pain in the left groin and the back. There was nearly total suppression of urine, with anxious countenance, hurried breathing, a hacking cough, headache, and "pain at the heart". The pulse was intermittent and rapid. There was no murmur on ausculta. tion; but the normal cardiac rhythm was replaced by five or six " hurried beats", followed by a distinct pause, and then repeated.

The patient was placed between blankets, the affected joints swathed in cotton-wool, a linseed-meal poultice applied over the heart, and the following prescription ordered : $\mathrm{B}$ Acidi salicylici gr. 80; liquoris ammoniæ citratis $\bar{Z} \mathrm{ij}$; potassii iodidi gr. xv ; infusi aurantii ad 3 viij. An ounce to be taken every two hours. The medicine was begun at 2 P.M.; and at 6 P.M., after the administration of twenty grains of salicylic acid, the patient's friends noticed "a change". At 8 P.M., he was visited, and found perspiring profusely, quite rational, and feeling easier. The pulse was still irregular. The medicine was ordered to be given every hour during the night. Strong beef-tea, with a tablespoonful of brandy every two hours, had been given ad libitum from 2 o'clock, and was ordered to be continued in the night. Fifteen hours afterwards, he was again visited, and found moving his arms and legs quite freely, declaring himself "painless", and the only visible trace of the rheumatism was a faint blush on the left inner ankle. He had been sleepless and wandered a good deal during the night, wanting to get out of bed when the pain left the joints. The pulse was still intermittent ; but the heart's action was less tumultuous, and there was very little præcordial pain. He was ordered to be well rubbed with a dry warm blanket, care being taken to avoid exposure. A purgative of calomel and jalap was administered, and the medicine ordered to be given every four hours. The brandy was stopped and beef-tea continued. Cold to the head could not be borne, as it produced a general chill and made the patient feel uncomfortable.

From this time-i.e., twenty-one hours after the administration of the salicylic acid, during which time he had one hundred and seventy grains of the drug - there was no relapse of the rheumatism. The excitement, however, remained while the drug was continued; and, in spite of chloral and Battley's solution (ten grains of each every three hours), the sleeplessness persisted until its entire discontinuance twentyfour hours later. So delirious was he for two nights succeeding the disappearance of the rheumatism, that he was kept with difficulty in bed, and even struggled with those near him. The second night after the discontinuance of the acid, the patient slept soundly without a draught. By this time, the secretions were restored, and he was allowed to sit by the bedroom fire and have a liberal diet.

This case, I think, points to the physiological action of salicylic acid, and its power to arrest, in certain cases, a grave and troublesome disease. The case is both a parallel and contrast to Dr. Foster's, published in the JOURNaL of December 9 th. The parallelism is vivid in the sleeplessness and disturbed state of nervous system following its prolonged use; the contrast is equally remarkable, Dr. Foster finding the temperature undiminished, the articular pains "severe", and the rheumatism spreading, on the third and fourth days of its administration. I regret that the temperature was not taken in my case, to show the degree of fall in twelve hours. 